\title{
Real-World Treatment Patterns of
}

\section{Multiple-Inhaler Triple Therapy Among Patients with Chronic Obstructive Pulmonary Disease in UK General Practice}

\author{
Leah B Sansbury' \\ Chanchal Bains ${ }^{2}$ \\ David A Lipson (D) ${ }^{3,4}$ \\ Afisi S Ismaila $\mathbb{1 D}^{5,6}$ \\ Sarah H Landis ${ }^{5}$ \\ 'Value Evidence and Outcomes, \\ GlaxoSmithKline, Research Triangle Park, \\ NC, USA; ${ }^{2}$ Value Evidence and \\ Outcomes, GlaxoSmithKline, Uxbridge, \\ UK; ${ }^{3}$ Clinical Sciences, GlaxoSmithKline, \\ Collegeville, PA, USA; ${ }^{4}$ Perelman School \\ of Medicine, University of Pennsylvania, \\ Philadelphia, PA, USA; ${ }^{5}$ Value Evidence \\ and Outcomes, GlaxoSmithKline, \\ Collegeville, PA, USA; ${ }^{6}$ Department of \\ Health Research Methods, Evidence and \\ Impact, McMaster University, Hamilton, \\ ON, Canada
}

Introduction: Until recently, triple therapy for chronic obstructive pulmonary disease (COPD) has only been available through treatment with multiple inhalers. Evidence on real-world use of multiple-inhaler triple therapy (MITT), including duration of use and treatment patterns, is limited. Methods: A retrospective, observational study of electronic health records and hospital episodes in patients with COPD initiating MITT between 2013 and 2015 in the UK was performed. This study described patients initiating, treatment persistence and discontinuation, and prior and subsequent COPD treatments.

Results: Eligible patients $(\mathrm{N}=3825)$ had a mean age of 69.5 years; most were former or current smokers (95\%). The majority (86\%) initiated MITT with two inhalers and 14\% initiated with three inhalers. Mean duration of use was 5.1 (standard deviation: 4.6) months; $24 \%$ of patients persisted for 12 months. Patients who had significantly poorer lung function at baseline (12 months prior to initiating MITT) and had experienced significantly more moderate-to-severe acute exacerbation of COPD (AECOPD) and hospitalizations during the baseline period were more likely to persist for 12 months, compared with those who discontinued within 12 months. Most patients stepped down to an inhaled corticosteroid/ long-acting $\beta_{2}$-agonist combination (ICS/LABA; 48\%) or a long-acting muscarinic antagonist (LAMA; 45\%) after discontinuing MITT.

Conclusion: Initiation of MITT occurred in patients with clinically relevant symptoms and a history of AECOPD. Persistence varied and was most likely linked to disease severity, although more research is required to fully understand why patients discontinue MITT, the subsequent clinical consequences of therapy discontinuation, and the potential impact of newly available single-inhaler triple therapies.

Keywords: chronic obstructive pulmonary disease, COPD, multiple-inhaler triple therapy, MITT, general practice, real world, treatment patterns

\section{Introduction}

Chronic obstructive pulmonary disease (COPD) is a leading cause of mortality and morbidity worldwide and is predicted to become the third most common cause of death globally by 2030. ${ }^{1}$ The Global Initiative for Chronic Obstructive Lung Disease (GOLD) strategy document provides preferred treatment pathways for COPD, recommending an incremental approach as the disease state worsens. ${ }^{2}$ This involves the use of combinations of drug classes with different or complementary mechanisms of
Correspondence: Leah B Sansbury Value Evidence and Outcomes, GlaxoSmithKline, Building 5, 42 Moore Drive, Research Triangle Park, NC, 27709, USA

Tel + I 9198120719

Email leah.b.sansbury@gsk.com 
action. Short- and long-acting bronchodilators, including anticholinergics (short-acting muscarinic antagonists [SAMA] or long-acting muscarinic antagonists [LAMA]) and $\beta_{2}$-agonists (short-acting $\beta_{2}$-agonists [SABA] or longacting $\beta_{2}$-agonists [LABA]), are indicated for symptomatic relief and maintenance, while inhaled corticosteroids (ICS) are added for more severe disease associated with recurrent acute exacerbation of COPD (AECOPD). ${ }^{2}$

Triple therapy, a combination of ICS, LAMA, and LABA, is a recommended treatment option for patients with COPD who remain symptomatic or experience an AECOPD despite being treated with dual bronchodilators (GOLD D classification). ${ }^{2}$ COPD patients may also stepup to triple therapy following a concurrent diagnosis of asthma or worsening of symptoms. ${ }^{3}$ Until recently, triple therapy has only been available through treatment with multiple inhalers (multiple-inhaler triple therapy [MITT]); however, single-inhaler triple therapies (SITT) are now also approved in several regions, including Europe $^{4,5}$ and the US. ${ }^{6}$ Past observational research has shown that most patients step up to MITT from an ICS/ LABA combination or from LAMA monotherapy due to unsatisfactory improvements in symptoms. ${ }^{7-10}$ However, there is sparse evidence on real-world use of MITT once initiated, including duration of use and treatment patterns, specifically what treatments patients are using beforehand, and subsequent treatment after MITT discontinuation.

A previous retrospective, electronic health record (EHR) study conducted in the UK found that, shortly after an initial COPD diagnosis, $19 \%$ of the patients classified as GOLD A (GOLD 2013 classification), 28\% of GOLD B, $37 \%$ of GOLD C, and $46 \%$ of GOLD D were prescribed MITT. $^{10}$ In addition, almost $100 \%$ of the patients with COPD in this cohort stepped up to MITT by the eighth year after their initial COPD diagnosis. Another retrospective EHR study in the UK of LAMA monotherapy users found $43.6 \%$ received treatment escalation at a mean of 325 days after LAMA initiation. ${ }^{9}$

The recent FULFIL and IMPACT clinical trials evaluated once-daily ICS/LAMA/LABA SITT versus twice-daily ICS/ LABA dual therapy (FULFIL), or versus once-daily ICS/ LABA and LAMA/LABA dual therapies (IMPACT) in patients with COPD. Both studies reported improvements in lung function and health-related quality of life, and reductions in exacerbations with SITT. ${ }^{11,12}$ The IMPACT study also demonstrated a potential mortality benefit with SITT compared with LAMA/LABA dual therapy. ${ }^{14}$ Similarly, in a real-world study by Short et al, ${ }^{13}$ MITT demonstrated a mortality benefit versus twice-daily ICS/LABA dual therapy.

This current study aims to describe MITT use in patients with COPD in a UK primary care setting, prior to availability of single-inhaler regimens, including duration of therapy, clinical characteristics of patients who initiated inhaled triple therapy, and patient and disease factors that contribute to the pattern of prescribing and persistence of use.

\section{Objectives}

The objective of the study was to describe the patient demographics, disease burden, and healthcare resource utilization in the 12 months prior to initiating MITT, the immediately preceding treatment prior to MITT prescription, the duration of MITT use over the 12 months post initiation, and, among those who discontinued, the treatment modification that followed MITT discontinuation. An additional objective was to compare the disease burden at baseline of those patients who persisted on MITT for 12 months and those who discontinued MITT within that year.

\section{Methods}

\section{Study Design}

This observational study employed a retrospective cohort design to identify patients with COPD who initiated MITT treatment between June 2013 and June 2015 as recorded in the UK Clinical Practice Research Datalink (CPRD). This database is linked to the Hospital Episode Statistics (HES) dataset, which captures hospital care to ensure complete capture of clinical events, including AECOPD. The selected time frame captured treatment patterns after combination inhaler LAMA/LABAs were approved in the UK (2013 for indacaterol/glycopyrronium bromide, 2014 for umeclidinium/vilanterol, and 2015 for tiotropium/olodaterol), and prior to the approval of single-device triple therapies. ${ }^{14,15}$

\section{Data Source}

Data were obtained from the CPRD-GOLD database which collects data from primary care practices using the Vision electronic health record software. The CPRD-GOLD database covers approximately $8.5 \%$ of the UK population, including practices in England, Northern Ireland, Scotland, and Wales. It contains anonymized, longitudinal medical records of patients registered with contributing primary care practices across the UK. CPRD-GOLD data is linked with HES, a data warehouse containing anonymized details 
of all inpatient episodes of care, outpatient appointments and Accident \& Emergency attendances at National Health Service (NHS) hospitals in England (Independent Scientific Advisory Committee [ISAC] approval 17_270).

\section{Patient Inclusion/Exclusion Criteria}

In order to meet the dataset requirements for $\mathrm{CPRD}$, patients were required to have data available for the 12 months prior to initiating MITT, as well as 12 months of follow-up data after MITT initiation. They were required to be 35 years of age or older when the COPD medical code for diagnosis was recorded, and have a record of a forced expiratory volume in 1 second $\left(\mathrm{FEV}_{1}\right)$ /forced vital capacity (FVC) ratio of $<0.7$ at any time in their patient history. This COPD case definition has previously been validated. ${ }^{16,17}$ Patients with a code for a medical condition where COPD diagnosis can be a secondary condition at any time in their history were excluded from the analysis. This included conditions related to lung or bronchial developmental anomalies, degenerative processes (cystic fibrosis, pulmonary fibrosis), bronchiectasis, pulmonary resection, or other significant respiratory disorders other than COPD (but not including cancer) that can interfere with clinical COPD diagnosis or substantially change the natural history of the disease. Patients with a concomitant diagnosis of asthma or a history of asthma, which is common in this population, were not excluded from the study.

\section{Outcome Measures}

MITT use was defined as at least 1 day of overlap of an ICS, LAMA, and LABA in two or three devices during the observation period of June 2013 to June 2015; the first date of overlap observed during this period was defined as the index date. Continuous MITT use during the 12 months after the index date was estimated by calculating the duration for each prescription based on the number of units (inhalations, puffs) prescribed and the units that the patient was expected to take each day (numeric daily dose). Treatment was considered discontinued when there was a gap of longer than 30 days where any component of MITT was not prescribed. Only new initiators of MITT treatment were included in this study, which was defined as no prior use of MITT in the previous 12 months. The duration of continuous MITT use over the 12 months after initiation was defined by repeat prescriptions for all three components with at least 1 day of overlap, and no gap in any component of longer than 30 days. If a gap of longer than 30 days was observed in any of the three components, MITT was considered discontinued. The baseline disease burden among patients who persisted on MITT for the 12 months of observation, and patients who discontinued MITT treatment, were described.

\section{Data Analysis}

Categorical variables were described by count and percentages, and continuous variables were described by mean and standard deviation (SD). A Chi-squared test was used to analyze differences in baseline disease burden among patients who persisted on MITT for 12 months and those who discontinued treatment.

\section{Results}

\section{Baseline Characteristics}

A total of 3825 patients were identified as new initiators of MITT treatment during the observational period and met the eligibility requirements (Table 1). The mean age of MITT initiators was 69.5 years and just over half (54\%) were male; $95 \%$ were former or current smokers, 34\% had a normal body mass index (BMI), and 61\% were overweight or obese.

The baseline (12 months prior to initiating MITT treatment) disease burden among MITT initiators is illustrated in Table 1. Among the total patient population, 55\% had a Medical Research Council (MRC) score $\geq 3$ (dyspnea limits walking pace [slower than others] and person stops to catch breath), and approximately $40 \%$ of the patients were classified as having severe or very severe airflow limitation with a lung function classified as $\mathrm{FEV}_{1}<50 \%$ predicted. The majority of patients were infrequent exacerbators; $70.6 \%$ of the patients had $<2$ moderate or severe AECOPDs in the year prior to MITT initiation. Around half of patients had at least one moderate or severe AECOPD in the year prior to MITT initiation and approximately one-third experienced at least two AECOPD events; $13 \%$ experienced at least one event leading to hospitalization.

\section{MITT Use and Persistence}

Among the 3825 patients who initiated MITT, 86\% initiated using two inhalers and the remainder (14\%) initiated with three inhalers (Table 2). In the year prior to initiation, most patients were using either ICS/LABA $(52 \%)$ or LAMA (31\%); only $3 \%$ of the patients stepped up from a LAMA/LABA and a small proportion (6\%) were maintenance treatment naïve (Figure 1). The mean duration of MITT use among the study cohort was 5.1 months (SD: 4.6 months). Around half of those who 
Table I Patient Characteristics and Disease Burden at Baseline

\begin{tabular}{|c|c|}
\hline & $\begin{array}{l}\text { Patients with COPD Initiating } \\
\text { MITT }(\mathrm{N}=3825)\end{array}$ \\
\hline \multicolumn{2}{|l|}{ Age, years } \\
\hline Mean (SD) & $69.5(10.5)$ \\
\hline Median & 70.0 \\
\hline Male, n (\%) & $2045(53.5)$ \\
\hline \multicolumn{2}{|l|}{ Smoking status, $\mathrm{n}(\%)^{\mathrm{a}}$} \\
\hline Former smoker & $2109(55.1)$ \\
\hline Current smoker & $1540(40.3)$ \\
\hline Never smoker & $176(4.6)$ \\
\hline \multicolumn{2}{|l|}{ BMI, n (\%) ${ }^{a, b, c}$} \\
\hline Normal $(18.5$ to $<25.0)$ & $1240(33.6)$ \\
\hline Overweight & $1194(32.4)$ \\
\hline$(25.0$ to $<30.0)$ & \\
\hline Obese $(\geq 30.0)$ & $1063(28.8)$ \\
\hline $\begin{array}{l}\text { Moderate/severe dyspnea, } \\
\text { n (\%) }{ }^{\text {a,d,e }}\end{array}$ & $1948(54.9)$ \\
\hline \multicolumn{2}{|l|}{$\begin{array}{l}\text { Lung function, GOLD grade, } \\
\mathrm{n}(\%)^{\mathrm{a}, \mathrm{e}}\end{array}$} \\
\hline $\begin{array}{l}\text { Mild }(\mathrm{FEV}, \geq 80 \% \\
\text { predicted) }\end{array}$ & $187(7.6)$ \\
\hline $\begin{array}{l}\text { Moderate }\left(50 \% \leq \mathrm{FEV}_{\mathrm{I}}\right. \\
<80 \% \text { predicted })\end{array}$ & $1270(51.4)$ \\
\hline $\begin{array}{l}\text { Severe }\left(30 \% \leq \mathrm{FEV}_{1}<50 \%\right. \\
\text { predicted) }\end{array}$ & $877(35.5)$ \\
\hline $\begin{array}{l}\text { Very severe }\left(\mathrm{FEV}_{1}<30 \%\right. \\
\text { predicted) }\end{array}$ & $138(5.6)$ \\
\hline \multicolumn{2}{|l|}{ AECOPD events, $n(\%)^{a, f}$} \\
\hline 0 & $162 \mid(42.4)$ \\
\hline 1 & $1077(28.2)$ \\
\hline$\geq 2$ & II $27(29.5)$ \\
\hline >I Hospitalized event & $488(12.8)$ \\
\hline
\end{tabular}

Notes: ${ }^{a}$ All variables measured in the 12 months prior to initiation of MITT; bercentages are based on non-missing values; ' not shown are underweight BMI category (5.0\%), and missing BMI data (3.6\%); ${ }^{\mathrm{d} M R C}$ score $\geq 3$ (mMRC score $\geq 2$ ); ${ }^{e}$ percentages are based on non-missing values: $7.2 \%$ missing MRC score and $35.4 \%$ missing spirometry data; ${ }^{f}$ defined by any moderate or severe (hospitalized) acute exacerbation of COPD event.

Abbreviations: AECOPD, acute exacerbation of COPD; BMI, body mass index; COPD, chronic obstructive pulmonary disease; $\mathrm{FEV}_{\mathrm{l}}$, forced expiratory volume in I second; GOLD, Global Initiative for Chronic Obstructive Lung Disease; MITT, multiple-inhaler triple therapy; MRC, Medical Research Council; mMRC, modified Medical Research Council; SD, standard deviation.

initiated MITT (51\%) only persisted on continuous therapy for less than 3 months; about one-quarter used MITT continuously for the full 12 months of observation (Table 2). Among those patients who discontinued MITT during the 12 months of observation, almost $9 \%$ re-initiated MITT within that year.
Table 2 MITT Use and Persistence

\begin{tabular}{|c|c|}
\hline & $\begin{array}{l}\text { Patients with COPD Initiating } \\
\text { MITT }(\mathrm{N}=3825)\end{array}$ \\
\hline \multicolumn{2}{|l|}{$\begin{array}{l}\text { Number of devices } \\
\text { comprising MITT, n (\%) }\end{array}$} \\
\hline 2 & $3302(86.3)$ \\
\hline 3 & $523(I 3.7)$ \\
\hline \multicolumn{2}{|l|}{$\begin{array}{l}\text { Duration of continuous MITT } \\
\text { use, } n(\%)\end{array}$} \\
\hline$<1$ month & $535(14.0)$ \\
\hline$\geq 1$ to $<2$ months & $978(25.6)$ \\
\hline$\geq 2$ to $<3$ months & 439 (1I.5) \\
\hline$\geq 3$ to $<6$ months & $513(13.4)$ \\
\hline$\geq 6$ to $<12$ months & $450(11.8)$ \\
\hline 12 months & $910(23.8)$ \\
\hline Mean (SD), months & $5.1(4.6)$ \\
\hline \multirow[t]{2}{*}{ Median, months } & 2.86 \\
\hline & $\begin{array}{l}\text { Patients with COPD Who } \\
\text { Discontinued MITT }(n=266 \mathrm{I})\end{array}$ \\
\hline \multicolumn{2}{|l|}{$\begin{array}{l}\text { Prescribed therapy after MITT } \\
\text { discontinuation, } n(\%)^{a}\end{array}$} \\
\hline ICS/LABA & I $280(48.1)$ \\
\hline ICS/LAMA & $70(2.6)$ \\
\hline LAMA/LABA & $50(1.9)$ \\
\hline LABA & $4(0.2)$ \\
\hline LAMA & II 97 (45.0) \\
\hline ICS & $33(1.2)$ \\
\hline No further treatment & $27(1.0)$ \\
\hline
\end{tabular}

Notes: anly the first modification episode in the 12 months after MITT initiation was recorded; $253(8.7 \%)$ patients, who reinitiated MITT after >30-day gap, are excluded from the denominator.

Abbreviations: COPD, chronic obstructive pulmonary disease; ICS, inhaled corticosteroid; LABA, long-acting $\beta_{2}$-agonist; LAMA, long-acting muscarinic antagonist; MITT, multiple-inhaler triple therapy.

\section{Prescribed Therapy After MITT Discontinuation}

Among the patients who met the definition for discontinuation ( $n=2661)$, approximately half stepped down to an ICS/ LABA (48\%) and 45\% stepped down to a LAMA (Table 2). Only a small proportion of patients (1\%) ceased the ICS component and stepped down to a dual LAMA/LABA.

\section{Baseline Disease Burden by Persistence of MITT Use}

Patients who persisted on MITT for a full 12 months (911 patients, 24\%) had significantly poorer baseline lung function $\left(\mathrm{FEV}_{1}<50 \%\right.$ predicted, $\left.\mathrm{p}<0.001\right)$, 


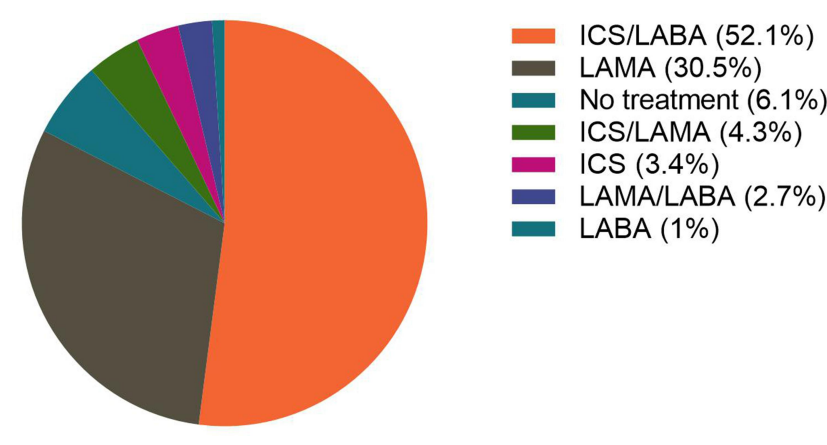

Figure I Treatment immediately preceding MITT initiation.

Abbreviations: ICS, inhaled corticosteroid; LABA, long-acting $\beta_{2}$-agonist; LAMA, long-acting muscarinic antagonist; MITT, multiple-inhaler triple therapy.

a significantly higher number of prior moderate-tosevere AECOPD $(p=0.002)$ and a significantly greater number of prior hospitalized AECOPD $(\mathrm{p}<0.001)$, compared with patients who discontinued MITT during the study (Table 3).

\section{Discussion}

The results from the current study suggest that MITT tends to be prescribed to patients with COPD with a history of AECOPD, or to those who have clinically relevant symptoms, particularly with more severe symptomatic disease. In a previous study of stable COPD patients in Japanese clinical practice, more than half of patients stepped up to inhaled triple therapy due to unsatisfactory symptom improvement, irrespective of airflow limitation level. ${ }^{8}$ While few patients stepped up or down to a dual LAMA/ LABA in this study, this may be explained by the fact that these drugs were only recently approved prior to the study observational period and may not have been readily available to prescribers and patients.

In a US database study, the proportion of patients progressing to triple therapy was $28 \%$ for those receiving monotherapy, $20 \%$ for ICS/LABA dual therapy, and $42 \%$ for LAMA/LABA dual therapy, with the majority making the transition within 1 year of initiation for each therapy. ${ }^{18}$ In a US Medicare study, the incidence rate for MITT initiation was 0.018 and 0.027 per 100 patient-days in patients initiating LAMA/LABA and ICS/LABA, respectively; the LAMA/LABA initiators had a 35\% lower risk of progression to MITT over 12 months following initiation. ${ }^{19}$ A UK study recently illustrated that patients with COPD who were receiving $\mathrm{LABA}$ were more likely to add an additional maintenance therapy than those receiving a LAMA, and while patients who were treated with a LAMA primarily initiated MITT by adding an ICS/LABA, LABA monotherapy users typically received dual therapy prior to initiating MITT. ${ }^{20}$ In the current study, most patients were receiving either an ICS/ LABA $(52 \%)$ or LAMA (31\%) in the year prior to MITT initiation. According to current COPD treatment guidelines, blood eosinophil counts should be taken into consideration when deciding whether to initiate ICS treatment in combination with a LABA and/or LAMA. ${ }^{2}$ However, it is likely that blood eosinophil counts were not considered in the treatment decisions observed in the current study, since the study was conducted prior to the inclusion of this recommendation.

Generally, persistence with MITT regimens was found to be variable in this study, but was most often associated with baseline disease severity. Overall, patients who had severe airflow limitation, a history of any or multiple AECOPD, and

Table 3 Baseline Disease Burden by Persistence of MITT Use

\begin{tabular}{|c|c|c|c|}
\hline & Persisted on MITT I 2 Months & Persisted on MITT $<12$ Months & p-value \\
\hline Total, n (\%) & 911 (23.8) & $2914(76.2)$ & \\
\hline Moderate/severe dyspnea ${ }^{\mathrm{a}, \mathrm{b}, \mathrm{c}}$ & $56 \%$ & $55 \%$ & 0.52 \\
\hline $\mathrm{FEV}_{\mathrm{I}}<50 \%$ predicted $^{\mathrm{a}, \mathrm{c}}$ & $49 \%$ & $39 \%$ & $<0.001$ \\
\hline \multicolumn{4}{|l|}{ AECOPD events ${ }^{\mathrm{a}, \mathrm{d}}$} \\
\hline 0 & $37.5 \%$ & $43.9 \%$ & 0.002 \\
\hline I & $29.5 \%$ & $27.7 \%$ & \\
\hline$\geq 2$ & $32.9 \%$ & $28.4 \%$ & \\
\hline$\geq I$ Hospitalized events & $16 \%$ & $12 \%$ & $<0.001$ \\
\hline
\end{tabular}

Notes: ${ }^{a}$ All variables measured in the 12 months prior to initiation of MITT; ${ }^{b} \mathrm{MRC}$ score $\geq 3$ (mMRC score $\geq 2$ ); ${ }^{\mathrm{c}}$ percentages are based on non-missing values: $7.2 \%$ missing MRC score and $35.4 \%$ missing spirometry data; ${ }^{d}$ defined by any moderate or severe (hospitalized) AECOPD event.

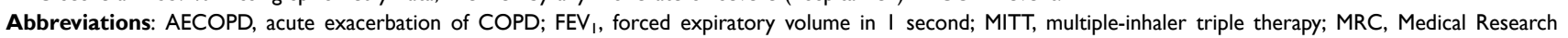
Council; mMRC, modified Medical Research Council. 
who experienced a hospitalized AECOPD event in the 12 months prior to initiation were more likely to persist with MITT for the full 12 months. Around three-quarters of patients in our study discontinued MITT before reaching the end of the 12-month observation period. Previous studies of patients with COPD in real-world settings have also reported low adherence or persistence with MITT. ${ }^{21,22}$ Another study of COPD patients who escalated to triple therapy found $18 \%$ continued use, $7.2 \%$ discontinued treatment permanently, $27.9 \%$ discontinued temporarily, and $46.7 \%$ switched therapy during the 18 months following escalation. ${ }^{23}$ Potential reasons for the low treatment persistence observed include patient misunderstanding of medications, difficulty in using the inhaler devices, or because of an improvement in, or lack of, symptoms. ${ }^{24}$

Although not investigated in this study, the benefits of MITT compared with single and dual therapy are apparent in prospective clinical studies. Two trials have demonstrated better improvements in St George's Respiratory Questionnaire (SGRQ) score, less reliance on rescue medication, better lung function and a lower risk of AECOPD in patients on inhaled triple therapy compared with those on mono and dual therapies. ${ }^{25,26}$ The recent TRILOGY and TRINITY studies also provided evidence in 52-week, randomized, controlled studies of superior clinical benefit with fixed-dose triple therapy (beclomethasone dipropionate [BDP]/glycopyrronium[GLY]/formoterol [FOR]) over LAMA monotherapy or ICS/LABA treatment, specifically relating to improvements in lung function and the prevention of exacerbations. ${ }^{27}$ Similarly, the TRIBUTE study demonstrated the superiority of the same triple ICS/LAMA/LABA (BDP/GLY/FOR) fixed-dose combination in reducing the rate of moderate-to-severe exacerbations in individuals with symptomatic COPD when compared with a LAMA/LABA combination. $^{28}$ The importance of the results from the TRILOGY, TRINITY and TRIBUTE studies is highlighted by the DYNAGITO study, which failed to show a meaningful benefit with dual-therapy LAMA/LABA (tiotropium [TIO]/olodaterol [OLO]) versus LAMA monotherapy in patients with COPD and a history of exacerbations. ${ }^{29}$ Once-daily, single-inhaler, triple therapy with fluticasone furoate (FF)/umeclidinium (UMEC)/vilanterol (VI) also demonstrated significant improvements in symptoms (as indicated by an improvement in SGRQ score of $\geq 4$ units) and quality of life, and reductions in AECOPD compared with twice-daily budesonide (BUD)/FOR (ICS/LABA) in the FULFIL study. ${ }^{11,12}$ In the IMPACT study, FF/UMEC/ VI single-inhaler triple therapy was associated with a lower
AECOPD rate compared with LAMA/LABA (UMEC/VI) and ICS/LABA (FF/VI), and clinically meaningful improvement in SGRQ score (defined as a change of $\geq 4$ units from baseline). While the difference between triple-therapy and dual-therapy comparators in SGRQ score improvement remained below the threshold for a clinically meaningful improvement, patients on triple therapy were significantly more likely to respond to treatment (in terms of symptoms, as defined by a decrease in SGRQ total score of $\geq 4$ units vs baseline) compared with patients receiving UMEC/VI or ICS/LABA. ${ }^{12}$

It should also be noted that LAMA/LABA (TIO/OLO) dual therapy has been shown to be more effective than ICS/LABA combinations for the improvement of lung function in COPD patients. ${ }^{30,31}$ Overall, the evidence suggests that individuals with COPD, who are most often prescribed triple therapy due to the severity of their condition, can not only gain further clinical benefits compared with mono- or dual-therapy, but that delivery in a single inhaler could have the potential to further enhance treatment persistence rates beyond those with MITT.

Observational studies of triple therapy for COPD maintenance have provided mixed results regarding the comparison of dual and triple therapy. In the DACCORD study, a real-world observational study of ICS/LAMA/ LABA versus LAMA/LABA, matched-pairs analysis in two subgroups of 1046 patients with COPD demonstrated a significantly lower exacerbation rate for patients receiving LAMA/LABA versus ICS/LAMA/LABA (exacerbation in $15.5 \%$ vs $26.6 \%$ of patients; $\mathrm{p}<0.001)$. Mean improvement from baseline in COPD Assessment Test (CAT) scores was also significantly improved with LAMA/LABA versus ICS/LAMA/LABA (-2.9 vs -1.4 , respectively; $\mathrm{p}<0.001)$. The percentage of patients with a clinically relevant improvement (CAT score $\geq 2$-unit change from baseline) was also significantly higher in patients receiving LAMA/LABA compared with tripletherapy users $(62 \%$ vs $47 \%$, respectively; $p<0.001) .^{32}$ In a UK primary care database study of 31,034 COPD patients, exacerbation risk was lower in LABA/ICS users, but the same in triple therapy and LAMA/LABA users. $^{33}$ A matched cohort study using a US Medicare claims database observed fewer severe COPD exacerbations for LAMA/LABA users compared with triple therapy $(9.0 \%$ vs $16.1 \%)$, and the LAMA/LABA users had a longer time to these events. ${ }^{34}$ A claims data study in France observed a similar number of COPD exacerbations for triple- and dual-therapy users in a 12-month period (2.4 
vs 2.3 , respectively; $\mathrm{p}=0.45$ ), but the patients receiving triple therapy were more likely to receive oral corticosteroids $(49.1 \%$ vs $40.4 \%, \mathrm{p}=0.003)$ or be hospitalized for COPD (35.3\% vs $25.1 \%, \mathrm{p}=0.002) .{ }^{35}$ In a real-world setting of triple-therapy initiators matched to LAMA/LABA initiators, the risk of COPD exacerbation was similar for each group; however, the triple therapy combination was more effective for patients with significant eosinophilia or frequent exacerbations. ${ }^{36}$

This difference in outcomes may be, at least in part, due to differences in the populations that receive triple therapy in clinical trials (patients with a history of exacerbations) compared with the clinic (may be prescribed in the absence of exacerbation history). ${ }^{9,10,18}$ Conversely, in the OUTPUL study of 5717 patients with COPD initiating new maintenance regimens (ICS/LABA or ICS/LABA plus TIO), the hazard ratio (HR) for experiencing COPD exacerbations was 0.68 (95\% confidence interval [CI]: $0.48,0.98)$ for patients receiving triple therapy versus dual therapy. ${ }^{37} \mathrm{~A}$ matched cohort of 1647 patients with COPD in a UK primary care database found that initiation of triple therapy reduced exacerbation risk (HR $0.87,95 \%$ CI $0.76-0.99$ ) compared with LAMA/LABA dual therapy. ${ }^{38}$ This is clearly more aligned with the above clinical studies and the current observational study, perhaps due to the different prescribing patterns between the countries in which these observational studies were conducted.

There are several strengths to this study, including the real-world context and large size of the dataset; the CPRDGOLD database is broadly representative of the UK population in terms of age, gender and socio-economic status, ${ }^{39}$ further supporting the validity of its findings. However, several limitations also need to be considered when interpreting these findings. Patients who were experiencing COPD symptoms but had not yet received a COPD diagnosis were not captured in the study. Also, while we used validated algorithms for identifying patients with COPD that have high sensitivity and positive predictive value, ${ }^{16,17}$ there is the potential for general practitioners to misdiagnose asthma as COPD and vice versa, particularly in patients aged 40 years and older. ${ }^{40}$ The fact that $5 \%$ of the COPD patients included in this study were 'never-smokers' indicates a possibility of misdiagnosis. While previous research has shown that the spirometry tracings used to diagnose and manage COPD in the UK are of high quality, ${ }^{17}$ the primary care record does not always include pre- or post-bronchodilator status and therefore there may be some misclassification of disease in our cohort. Secondly, the algorithm describing MITT is based on prescriptions for two to three inhalers that have different dosing regimens, and assumptions on dosing and duration of treatment were used to construct periods of triple therapy and windows agreed to allow for gaps between specific periods of use. Overall, such an algorithm is prone to inconsistencies and issues with both specificity and sensitivity; however, it is an improvement over simple identification of periods of simultaneous prescribing date and usage.

One further limitation to be considered is that at the time of the study (2013-2015), devices combining fixeddose LAMA and LABA had only recently been approved as a maintenance treatment for COPD in the UK. It is possible that there was limited access to newly approved LAMA/LABA combinations during the observation period, which may have led to fewer patients receiving these drugs compared with subsequent years. In addition, as the study did not include a control group of patients who did not initiate MITT, the factors affecting initiation of MITT could not be identified. Finally, electronic health records are limited in capturing variability in adherence to MITT use, treatment "holidays", and reasons for lack of adherence and discontinuation are not systematically recorded.

\section{Conclusions}

Overall, the results of this current study suggest that most patients prescribed MITT have a history of clinically relevant symptoms and AECOPD, and that subsequent treatment persistence with this type of regimen is variable, but may be associated with the patient's underlying disease severity. Patients who persisted with MITT for 12 months had significantly poorer lung function during the baseline period, had a significantly higher number of prior moderate-to-severe AECOPD, and a significantly greater number of hospitalized AECOPD. Additional research on patient and clinical characteristics for those who persist with MITT versus those who discontinue MITT will provide important additional insight into treatment decisionmaking. It would also be prudent to investigate the newly available once- and twice-daily SITT regimens in populations where a high discontinuation rate with MITT is predicted.

\section{Abbreviations}

AECOPD, acute exacerbation of chronic obstructive pulmonary disease; BDP, beclomethasone dipropionate; BMI, body mass index; BUD, budesonide; CAT, COPD Assessment Test; CI, confidence interval; COPD, chronic obstructive pulmonary disease; CPRD, Clinical 
Practice Research Datalink; FOR, formoterol; GLY, glycopyrronium; HER, electronic health record; HES, Hospital Episode Statistics; HR, hazard ratio; FEV 1 , forced expiratory volume in 1 second; FF, fluticasone furoate; FVC, forced vital capacity; GOLD, Global Initiative for Chronic Obstructive Lung Disease; ICS, inhaled corticosteroid; ISAC, Independent Scientific Advisory Committee; LABA, long-acting $\beta_{2}$-agonist; LAMA, long-acting muscarinic antagonist; MITT, multiple-inhaler triple therapy; MRC, Medical Research Council; mMRC, modified Medical Research Council; NHS, National Health Service; OLO, olodaterol; SABA, short-acting $\beta_{2}$-agonist; SAMA, short-acting muscarinic antagonist; SD, standard deviation; SGRQ, St George's Respiratory Questionnaire; SITT, single-inhaler triple therapy; TIO, tiotropium; UMEC, umeclidinium; VI, vilanterol.

\section{Data Sharing Statement}

The data analyzed in this publication are derived from the Clinical Practice Research Datalink (www.cprd.com) and Hospital Episode Statistics database (https://digital.nhs.uk/ data-and-information/data-tools-and-services/data-services /hospital-episode-statistics). Therefore, it cannot be broadly disclosed or made publicly available at this time. Access to each database can be requested via the respective websites.

\section{Ethics Approval and Informed Consent}

Approval of this study was provided by GSK Protocol Review Committee and by the Independent Scientific Advisory Committee (ISAC), which reviewed the protocol and approved access to Clinical Practice Research Datalink data (ISAC study no. 17_270). Patient consent was not required as anonymized patient-level data were used in this analysis.

\section{Acknowledgments}

Writing and editing assistance was provided by Page Abrahamson. Additional editorial support (in the form of writing assistance, collating author comments, assembling tables/figures, grammatical editing and referencing) was provided by Tom Gallagher, $\mathrm{PhD}$ of Gardiner-Caldwell Communications (Macclesfield, UK), and Tony Reardon of Aura (a division of Spirit Medical Communications Group Limited), and was funded by GlaxoSmithKline. This analysis was presented as an oral presentation at the American Thoracic Society (ATS) International Conference held in San Diego, CA, USA, 18-23 May 2018. Trademarks are the property of their respective owners.

\section{Author Contributions}

All authors were involved in study conception and design, and data analysis and interpretation. All authors contributed to writing/review of the manuscript and provided final approval of the manuscript.

\section{Funding}

This study was funded by GlaxoSmithKline (PRJ2546).

\section{Disclosure}

LBS, ASI, and DAL are employees, and hold shares in, GlaxoSmithKline. CB was a contingent worker on assignment to GlaxoSmithKline at the time the study was performed. ASI is also an unpaid faculty member at McMaster University in Canada. SHL conducted the research while working at GlaxoSmithKline, and is now employed by BioMarin.

\section{References}

1. World Health Organization (WHO). Chronic obstructive pulmonary disease (COPD). Available from: https://www.who.int/respiratory/ copd/burden/en/. Accessed August 03, 2020.

2. Global Initiative for Chronic Obstructive Lung Disease (GOLD). 2020 global strategy for the diagnosis, management, and prevention of chronic obstructive pulmonary disease. Available from: https://gold copd.org/wp-content/uploads/2019/11/GOLD-2020-REPORT-ver1. 0wms.pdf. Accessed August 03, 2020.

3. Global Initiative for Asthma (GINA). Global strategy for asthma management and prevention (2020 update). Available from: https:// ginasthma.org/wp-content/uploads/2020/06/GINA-2020-

report_20_06_04-1-wms.pdf. Accessed February 02, 2021.

4. EMA. Trimbow beclometasone/formoterol/glycopyrronium bromide; 2017. Available from: https://www.ema.europa.eu/en/medicines/ human/EPAR/trimbow. Accessed March 30, 2019.

5. EMA. Trelegy Ellipta; 2018. Available from: https://www.ema.europa. eu/en/medicines/human/EPAR/trelegy-ellipta. Accessed March 30, 2019.

6. FDA. Trelegy Ellipta (fluticasone furoate $100 \mathrm{mcg}$, umeclidinium 62.5 $\mathrm{mcg}$, and vilanterol $25 \mathrm{mcg}$ ) Inhalation Powder; 2017. Available from: https://www.accessdata.fda.gov/drugsatfda_docs/label/2017/ 209482s000lbl.pdf. Accessed March 30, 2019.

7. Bogart M, Stanford RH, Reinsch T, Hull M, Buikema A, Hulbert E. Clinical characteristics and medication patterns in patients with COPD prior to initiation of triple therapy with ICS/LAMA/LABA: a retrospective study. Respir Med. 2018;142:73-80. doi:10.1016/j. rmed.2018.07.009

8. Miyazaki M, Nakamura H, Takahashi S, et al.; Keio COPD Comorbidity Research (K-CCR) group. The reasons for triple therapy in stable COPD patients in Japanese clinical practice. Int $J$ Chron Obstruct Pulmon Dis. 2015;10:1053-1059. doi:10.2147/COPD. S79864 
9. Hurst JR, Dilleen M, Morris K, Hills S, Emir B, Jones R. Factors influencing treatment escalation from long-acting muscarinic antagonist monotherapy to triple therapy in patients with COPD: a retrospective THIN-database analysis. Int $J$ Chron Obstruct Pulmon Dis. 2018;13:781-792. doi:10.2147/COPD.S153655

10. Brusselle G, Price D, Gruffydd-Jones K, et al. The inevitable drift to triple therapy in COPD: an analysis of prescribing pathways in the UK. Int $J$ Chron Obstruct Pulmon Dis. 2015;10:2207-2217. doi:10.2147/COPD.S91694

11. Lipson DA, Barnacle H, Birk R, et al. FULFIL Trial: once-daily triple therapy for patients with chronic obstructive pulmonary disease. Am $J$ Respir Crit Care Med. 2017;196(4):438-446. doi:10.1164/ rccm.201703-0449OC

12. Lipson DA, Barnhart F, Brealey N, et al.; IMPACT Investigators. Once-daily single-inhaler triple versus dual therapy in patients with COPD. $N$ Engl J Med. 2018;378(18):1671-1680. doi:10.1056/ NEJMoa1713901

13. Short PM, Williamson PA, Elder DHJ, Lipworth SIW, Schembri S, Lipworth BJ. The impact of tiotropium on mortality and exacerbations when added to inhaled corticosteroids and long-acting $\beta$-agonist therapy in COPD. Chest. 2012;141(1):81-86. doi:10.1378/chest.11-0038

14. GlaxoSmithKline. Trelegy Ellipta 92 micrograms $/ 55$ micrograms $/ 22$ micrograms inhalation powder, pre-dispensed summary of product characteristics; 2020. Available from: https://www.medicines.org.uk/ emc/product/8666/smpc\#gref. Accessed April 16, 2021.

15. Chiesi Limited. Trimbow 87 micrograms $/ 5$ micrograms $/ 9$ micrograms pressurised inhalation, solution summary of product characteristics; 2021. Available from: https://www.medicines.org.uk/ emc/medicine/33828\#gref. Accessed April 16, 2021.

16. Quint JK, Müllerova H, DiSantostefano RL, et al. Validation of chronic obstructive pulmonary disease recording in the Clinical Practice Research Datalink (CPRD-GOLD). BMJ Open. 2014;4(7): e05540. doi:10.1136/bmjopen-2014-005540

17. Rothnie KJ, Müllerová H, Goss H, Chandan J, Quint JK. P223 Validity and interpretation of spirometry for patients in primary care. Thorax. 2015;70(Suppl 3):A188-A190. doi:10.1136/thoraxjnl-2015-207770.359

18. Lane DC, Stemkowski S, Stanford RH, Tao Z. Initiation of triple therapy with multiple inhalers in chronic obstructive pulmonary disease: an analysis of treatment patterns from a U.S. retrospective database study. J Manag Care Spec Pharm. 2018;24 (11):1165-1172. doi:10.18553/jmcp.2018.24.11.1165

19. Moretz C, Sharpsten L, Bengtson LGS, et al. Real-world effectiveness of umeclidinium/vilanterol versus fluticasone propionate/salmeterol as initial maintenance therapy for chronic obstructive pulmonary disease (COPD): a retrospective cohort study. Int J Chron Obstruct Pulmon Dis. 2019;14:1721-1737. doi:10.2147/COPD.S204649

20. Landis SH, Wurst K, Le HV, Bonar K, Punekar YS. Can assessment of disease burden prior to changes in initial COPD maintenance treatment provide insight into remaining unmet needs? A retrospective database study in UK primary care. COPD. 2017;14(1):80-85. doi:10.1080/15412555.2016.1240159

21. Bogart M, Stanford RH, Lalibert F, Germain G, Wu JW, Duh MS. Medication adherence and persistence in chronic obstructive pulmonary disease patients receiving triple therapy in a USA commercially insured population. Int $J$ Chron Obstruct Pulmon Dis. 2019;14:343-352. doi:10.2147/COPD.S184653

22. Calabria S, Ronconi G, Dondi L, et al. Open triple therapy for chronic obstructive pulmonary disease: patterns of prescription, exacerbations and healthcare costs from a large Italian claims database. Pulm Pharmocol Ther. 2020;61:101904. doi:10.1016/j. pupt.2020.101904

23. Meeraus W, Wood R, Jakubanis R, et al. COPD treatment pathways in France: a retrospective analysis of electronic medical record data from general practitioners. Int $J$ Chron Obstruct Pulmon Dis. 2019;14:51-63. doi:10.2147/COPD.S181224
24. Bender BG, Vecino RA, McGrath K, Jones S. Comparative analysis of persistence to treatment among patients with asthma or COPD receiving AirFluSal Forspiro or Seretide Diskus salmeterol/fluticasone propionate combination therapy. J Allergy Clin Immunol Pract. 2016;4(5):884-889. doi:10.1016/j.jaip.2016.07.006

25. Kerwin E, Siler T, Tombs L, Sousa AR, Singletary K, Church A. Triple therapy of umeclidinium and inhaled corticosteroid/longacting $\beta 2$-agonist (ICS/LABA) vs placebo + ICS/LABA in GOLD D patients. Eur Respir J. 2015;46(suppl59):PA1490. doi:10.1183/ 13993003.congress-2015.PA1490

26. Lee SD, Xie CM, Yunus F, Itoh Y, Su R. Efficacy and tolerability of budesonide/formoterol added to tiotropium compared with tiotropium alone in Asian patients with severe chronic obstructive pulmonary disease [abstract]. Am Thorac Soc. 2014;A3768.

27. Singh D, Corradi M, Spinola M, et al. Triple therapy in COPD: new evidence with the extrafine fixed combination of beclomethasone dipropionate, formoterol fumarate, and glycopyrronium bromide. Int J Chron Obstruct Pulmon Dis. 2017;12:2917-2928. doi:10.2147/COPD.S146822

28. Papi A, Vestbo J, Fabbri L, et al. Extrafine inhaled triple therapy versus dual bronchodilator therapy in chronic obstructive pulmonary disease (TRIBUTE): a double-blind, parallel group, randomised controlled trial. Lancet. 2018;391(10125):1076-1084. doi:10.1016/ S0140-6736(18)30206-X

29. Calverley PMA, Anzueto AR, Carter K, et al. Tiotropium and olodaterol in the prevention of chronic obstructive pulmonary disease exacerbations (DYNAGITO): a double-blind, randomised, parallel-group, active-controlled trial. Lancet Respir Med. 2018;6 (5):337-344. doi:10.1016/S2213-2600(18)30102-4

30. Beeh KM, Derom E, Echave-Sustaeta J, et al. The lung function profile of once-daily tiotropium and olodaterol via Respimat ${ }^{\circledR}$ is superior to that of twice-daily salmeterol and fluticasone propionate via Accuhaler ${ }^{\circledR}$ (ENERGITO ${ }^{\circledR}$ study). Int $J$ Chron Obstruct Pulmon Dis. 2016;11:193-205. doi:10.2147/COPD.S95055

31. Miravitlles M, Urrutia G, Mathioudakis AG, Ancochea J. Efficacy and safety of tiotropium and olodaterol in COPD: a systematic review and meta-analysis. Respir Res. 2017;18(1):196. doi:10.1186/s12931017-0683-x

32. Buhl R, Criée CP, Kardos P, et al. Dual bronchodilation vs triple therapy in the "real-life" COPD DACCORD study. Int $J$ Chron Obstruct Pulmon Dis. 2018;13:2557-2568. doi:10.2147/COPD. $\mathrm{S} 169958$

33. Bloom CI, Douglas I, Usmani OS, Quint JK. Inhaled corticosteroid treatment regimens and health outcomes in a UK COPD population study. Int J Chron Obstruct Pulmon Dis. 2020;15:701-710. doi:10.2147/COPD.S241568

34. Palli SR, Frazer M, DuCharme M, Buikema AR, Anderson AJ, Franchino-Elder J. Differences in real-world health and economic outcomes among patients with COPD treated with combination tiotropium/olodaterol versus triple therapy. J Manag Care Spec Pharm. 2020;17:1-13. doi:10.18553/jmcp.2020.20159

35. Dalon F, Roche N, Belhassen M, et al. Dual versus triple therapy in patients hospitalized for COPD in France: a claims data study. Int $J$ Chron Obstruct Pulmon Dis. 2019;14:1839-1854. doi:10.2147/COPD.S214061

36. Suissa S, Dell-Aniello S, Ernst P. Comparative effects of LAMA-LABA-ICS vs LAMA LABA for COPD: cohort study in real-world clinical practice. Chest. 2020;157(4):846-855. doi:10.1016/j.chest.2019.11.007

37. Ferroni E, Belleudi V, Sascini S, et al.; OUTPUL Study Group. Role of tiotropium in reducing exacerbations of chronic obstructive pulmonary disease when combined with long-acting $\beta_{2}$-agonists and inhaled corticosteroids: the OUTPUL study. J Clin Pharmacol. 2016;56(11):1423-1432. doi:10.1002/jcph.750. 
38. Voorham J, Corradi M, Papi A, et al. Comparative effectiveness of triple therapy versus dual bronchodilation in COPD. ERJ Open Res. 2019;5(3):00106-2019. doi:10.1183/23120541.00106-2019

39. Herrett E, Gallagher AM, Bhaskaran K, et al. Data resource profile: Clinical Practice Research Datalink (CPRD). Int $J$ Epidemiol. 2015;44(3):827-836. doi:10.1093/ije/dyv098
40. Tinkelman DG, Price DB, Nordyke RJ, Halbert RJ. Misdiagnosis of COPD and asthma in primary care patients 40 years of age and over. J Asthma. 2006;43(1):75-80. doi:10.1080/02770900500448738

\section{Publish your work in this journal}

The International Journal of COPD is an international, peer-reviewed journal of therapeutics and pharmacology focusing on concise rapid reporting of clinical studies and reviews in COPD. Special focus is given to the pathophysiological processes underlying the disease, intervention programs, patient focused education, and self management protocols. This journal is indexed on PubMed Central, MedLine and CAS. The manuscript management system is completely online and includes a very quick and fair peer-review system, which is all easy to use. Visit http://www.dovepress.com/testimonials.php to read real quotes from published authors. 